\title{
Socio-biologic Predictors of Active Cytomegalovirus Infection Among Pregnant Women in a Low-resource Setting
}

\author{
Awoleke Jacob Olumuyiwa ${ }^{1}$, Omoyajowo Adefunke Christianah ${ }^{2}$, Ajayi David Daisi ${ }^{3}$, \\ Awoleke Adeola Olabisi ${ }^{4}$ \\ ${ }^{1}$ Department of Obstetrics and Gynaecology, Ekiti State University, Ado-Ekiti, Nigeria \\ ${ }^{2}$ Department of Mathematics and Statistics, Bowen University, Osun State, Nigeria \\ ${ }^{3}$ Department of Medical Laboratory Science, Ekiti State University Teaching Hospital, Ado - Ekiti, Nigeria \\ ${ }^{4}$ School of Nursing, Ekiti State University Teaching Hospital, Ado - Ekiti, Nigeria
}

Email address:

jacob.awoleke@eksu.edu.ng(A. J. Olumuyiwa)

\section{To cite this article:}

Awoleke Jacob Olumuyiwa, Omoyajowo Adefunke Christianah, Ajayi David Daisi, Awoleke Adeola Olabisi. Socio-biologic Predictors of Active Cytomegalovirus Infection Among Pregnant Women in a Low-resource Setting. Journal of Gynecology and Obstetrics.

Vol. 7, No. 1, 2019, pp. 25-30. doi: 10.11648/j.jgo.20190701.14

Received: February 16, 2019; Accepted: March 22, 2019; Published: April 13, 2019

\begin{abstract}
Active maternal cytomegalovirus (CMV) infection is the bedrock of congenital CMV with its debilitating sequelae. Information on socio-biologic predictors of active maternal infection in southwest Nigeria is lacking. However, modifying locality-specific risk factors could reduce the burden of CMV. The aim of the study is to identify the socio-biologic determinants for active maternal CMV infection in a Nigerian setting. Using a cross-sectional design, ELISA kits were employed to quantify the anti-CMV IgG and IgM antibodies in the sera of consecutive antenatal attendees at the Ekiti State University Teaching Hospital (EKSUTH), Nigeria. Among the respondents, 23 (12.4\%) were seropositive for both anti-CMV IgG and IgM antibodies. The regression analysis showed that the likelihood of being seropositive for both anti-CMV IgG and IgM antibodies was predicted by having a child less than 5 years old (adjusted OR: 5.53; 95\% CI: $1.08-28.30 ; \mathrm{p}=0.04$ ), while those who were skilled workers were least likely to be seropositive for both antibodies (adjusted OR: 0.06 ; $95 \%$ CI: 0.01 $-0.95 ; \mathrm{p}=0.04$ ). Also, infection with cytomegalovirus was associated with pre-eclampsia (adjusted OR: 0.03 ; 95\% CI: 0.002 $-0.41 ; p=0.01)$. High prevalence of active maternal CMV infection was noted from the study, and this was associated with pre-eclampsia and caring for children under-5. Educating pregnant non-immune women about CMV and its prevention, coupled with the improvement in socio-economic status of the populace can reduce the burden in low-resource settings.
\end{abstract}

Keywords: Cytomegalovirus, Socio-biologic Predictors, Immunoglobulin M (IgM), Screening, Low-resource Setting

\section{Introduction}

Cytomegalovirus (CMV) is the commonest cause of intrauterine viral infection, occurring in $0.2 \%$ to $2.2 \%$ of all live births. Congenital CMV is the leading infectious cause of mental retardation and sensori-neural deafness globally [1]. About $20 \%$ to $30 \%$ of the neonates with symptomatic congenital infection will die from coagulopathy, hepatic dysfunction, or secondary bacterial infection [1]. The economic burden of congenital CMV in the United States was estimated at $\$ 1.86$ billion per year, with enormous negative impact on the quality of life of the affected toddlers and their parents $[2,3]$.

Pregnant women can be infected with CMV when they come in contact with the saliva or urine of an infected young child, or during sexual intercourse just before or during pregnancy [4]. Mother-to-child transmission of CMV is mainly the result of primary maternal CMV infection. However, there is increasing evidence that non-primary infections (usually following re-activation of a latent endogenous virus or re-infection by a viral strain from an exogenous source which differs from the previous strain in epitopes of envelope glycoproteins) could lead to 
symptomatic and severe neonatal/childhood outcomes $[5,6]$.

The best methods of establishing a diagnosis of maternal CMV infection are serological tests and virology. Once seroconversion to $\mathrm{CMV}$ in a previously seronegative woman is detected, a diagnosis of primary CMV infection can be made [1, 7]. However, since a documentation of seroconversion is rarely made (because women are not usually screened before pregnancy), the detection of CMV IgM has been used as a marker of active or recent CMV infection. Thus, the simultaneous detection of both CMVIgG and IgM in a screen-naïve pregnant woman may represent a primary infection [7].

Although the debilitating effects of congenital CMV are well-known from studies [1, 8, 9], clinicians and public health officials are still struggling to translate this knowledge into health promotion messages and protocols that can prevent CMV infections (in both mothers and their babies) in our environment. Up till date, in the developing countries, the burden of congenital CMV remains unknown because of the non-availability of reliable data [10]. Could the rate-limiting step be the poor understanding of the socio-biologic predictors of primary/non-primary CMV infection in our setting? Identifying the predictors of CMV infection in our locality would guide the development of preventive strategies to modify these socio-biologic determinants, thereby reducing the prevalence of the disease in our environment. This is the aim of this study.

\section{Methods}

This study was conducted in the antenatal clinics of the Ekiti State University Teaching Hospital (EKSUTH), Ado Ekiti, Ekiti State, between January 1st and March 31st, 2017. EKSUTH is the only state-owned tertiary health facility, serving the population within Ekiti State and its environs, who are majorly of Yoruba extraction.

During the study period, information about CMV was provided to pregnant women as part of their prenatal instructions. All antenatal attendees who consented to screening were interviewed using a proforma. The details required included age, parity, level of education, marital status, occupation, had a child below the age of 5 , history of miscarriages, intrauterine fetal demise and neonatal death. Results of $75 \mathrm{gm}$ oral glucose test (which was universally administered to pregnant women in our institution) were documented. Pre-eclampsia was defined as a blood pressure of $\geq 140 / 90 \mathrm{mmHg}$ on two occasions $\geq 6$ hours apart after 20 weeks of gestation, with proteinuria $\geq 2+$ by dipstick testing on a mid-stream urine specimen.

Thereafter, venous blood was obtained from each of the women and separated. The sera (initially stored at $-20^{\circ} \mathrm{C}$ before sample analysis) were then assayed for $\mathrm{CMV}$-specific immunoglobulin $\mathrm{G}$ (IgG) and immunoglobulin $\mathrm{M}$ (IgM) using separate enzyme-linked immunosorbent assay (ELISA) test kits (Rapid Diagnostics, Delhi, India) according to the manufacturer's specifications. Each kit included a microplate already pre-coated with anti-human CMV antibodies. After diluting the samples, the micro-plate was treated with $5 \mu \mathrm{l}$ of the diluted samples and incubated for 30 minutes at $37^{\circ} \mathrm{C}$. Any CMV antibodies present were captured by the solid phase.

After washing off all the unbound components in the wells, $100 \mu 1$ of the conjugate (containing enzyme-conjugated recombinant CMV antigens) was added to the sample wells of the micro-plate, and incubated again for 30 minutes at $37^{\circ} \mathrm{C}$. This was to detect the presence of CMV IgG and IgM antibodies in the samples.

After a second washing, 50 $\mu$ l each of Substrate A and Substrate B were added to all the wells, and the micro-plate was incubated at $37^{\circ} \mathrm{C}$ for 10 minutes. The enzymes acted on the mixture to generate an optical signal (blue) that was proportional to the amount of CMV IgG and IgM antibodies present in the sample. The enzymatic reaction was stopped by the addition of $50 \mu 1$ of an acid stop solution, producing a yellow colour in wells with positive samples. Test results were obtained by measuring and comparing the absorbance reading of the wells of the samples against the standards with a micro-plate reader at $450 / 630-700 \mathrm{~nm}$ within 30 minutes. The discriminatory values that identified the negative and positive populations were chosen in line with the manual's instructions.

The data obtained were entered into, and analyzed using the Statistical Package for Social Sciences version 20 (IBM SPSS, Chicago, USA). The results were expressed as a frequency table, and multivariate logistic regression analysis was employed for inferential purpose. The observed differences were adjudged to be significant when the $p$ value was $<0.05$.

\section{Results}

A total of 185 pregnant women were enrolled during the study period. Of these women, $41(22.2 \%)$ were seronegative for CMV, while $23(12.4 \%)$ were seropositive for both antiCMV IgG and IgM antibodies (Table 1).

Table 1. Seroprevalence of antibodies to CMV in the respondents, $n=185$.

\begin{tabular}{lll}
\hline Antibodies & Frequency (\%) & Explanation \\
\hline $\operatorname{IgG}(-), \operatorname{IgM}(-)$ & $41(22.2)$ & Non-immune; at risk of primary infection \\
$\operatorname{IgG}(+), \operatorname{IgM}(-)$ & $121(65.4)$ & Previous exposure to CMV \\
IgG (+), IgM (+) & $23(12.4)$ & Primary or non-primary active infection \\
Total & $185(100)$ & \\
\hline
\end{tabular}

Table 2 showed the socio-biologic characteristics of the respondents. Three $(1.6 \%)$ of the respondents were at the extremes of childbearing age, seven $(3.8 \%)$ were single, while $71(38.4 \%)$ were nulliparous women. Although 24 
(13\%) were unemployed, $155(83.8 \%)$ of the respondents were educated up to the tertiary level. About half of them (49.2\%) had children below the age of 5 years; five $(2.7 \%)$ and $6(3.2 \%)$ of the respondents had pre-eclampsia and previous history of neonatal death respectively.

The regression analysis with socio-biologic variables as co-variates was displayed in Table 3. The likelihood of being seropositive for both anti-CMV IgG and IgM antibodies was predicted by having a child less than 5 years old (adjusted OR: $5.53 ; 95 \%$ CI: $1.08-28.30 ; p=0.04$ ), while those who were skilled workers were least likely to be seropositive for both antibodies (adjusted OR: 0.06; 95\% CI: $0.01-0.95 ; \mathrm{p}=$ 0.04). Also, recent infection with cytomegalovirus was associated with pre-eclampsia (adjusted OR: 0.03 ; 95\% CI: $0.002-0.41 ; \mathrm{p}=0.01$ ).

Table 2. Characteristics of the respondents, $n=185$.

\begin{tabular}{ll}
\hline Characteristics & Frequency $(\%)$ \\
\hline Age (years) & $1(0.5)$ \\
$\leq 19$ & $182(98.4)$ \\
$20-39$ & $2((1.1)$ \\
$\geq 40$ & \\
Parity & $71(38.4)$ \\
0 & $114(61.6)$ \\
$1-4$ & \\
Level of Education & $30(16.2)$ \\
$\leq$ Secondary & $155(83.8)$ \\
Tertiary &
\end{tabular}

\begin{tabular}{ll}
\hline Characteristics & Frequency (\%) \\
\hline Occupation & $16(8.6)$ \\
Student & $24(13.0)$ \\
Unemployed & $63(34.1)$ \\
Unskilled & $60(32.4)$ \\
Semi-skilled & $22(11.9)$ \\
Skilled & \\
Marital status & $7(3.8)$ \\
Single & $178(96.2)$ \\
Married & \\
Had a child below 5 years & $94(50.8)$ \\
No & $91(49.2)$ \\
Yes & \\
History of miscarriages & $167(90.3)$ \\
No & $18(9.7)$ \\
Yes & \\
Previous intrauterine fetal demise & $174(94.1)$ \\
No & $11(5.9)$ \\
Yes & \\
Previous neonatal death & $179(96.8)$ \\
No & $6(3.2)$ \\
Yes & $182(98.4)$ \\
Gestational Diabetes Mellitus & $3(1.6)$ \\
No & \\
Yes & $180(97.3)$ \\
Pre-eclampsia & $5(2.7)$ \\
No & \\
Yes &
\end{tabular}

Table 3. Logistic regression analysis of predictors of CMV infection.

\begin{tabular}{|c|c|c|c|c|c|}
\hline \multirow{2}{*}{ Characteristics } & \multicolumn{2}{|c|}{ Anti-CMV IgG + IgM } & \multirow{2}{*}{ Adjusted OR } & \multirow{2}{*}{ 95\% C. I. } & \multirow{2}{*}{ p value } \\
\hline & Positive (\%) & Negative (\%) & & & \\
\hline \multicolumn{6}{|l|}{ Age (years) } \\
\hline$\leq 19$ & $0(0)$ & $1(100)$ & 1.00 & & \\
\hline $20-39$ & $23(12.6)$ & $159(87.4)$ & 4.457E8 & $0.00-\infty$ & 1.00 \\
\hline$\geq 40$ & $0(0)$ & $2(100)$ & 3.09 & $0.00-\infty$ & 1.00 \\
\hline \multicolumn{6}{|l|}{ Parity } \\
\hline 0 & $9(12.7)$ & $62(87.3)$ & 1.00 & & \\
\hline $1-4$ & $14(12.3)$ & $100(87.7)$ & 0.95 & $0.33-2.71$ & 0.93 \\
\hline \multicolumn{6}{|c|}{ Level of Education } \\
\hline$\leq$ Secondary & $4(13.3)$ & $26(86.7)$ & 1.00 & & \\
\hline Tertiary & $19(12.3)$ & $136(87.7)$ & 0.92 & $0.20-4.17$ & 0.91 \\
\hline \multicolumn{6}{|l|}{ Occupation } \\
\hline Student & $4(25)$ & $12(75)$ & 1.00 & & \\
\hline Unemployed & $2(8.3)$ & $22(91.7)$ & 0.17 & $0.02-1.68$ & 0.13 \\
\hline Unskilled & $10(15.9)$ & $53(84.1)$ & 0.30 & $0.05-1.89$ & 0.20 \\
\hline Semi-skilled & $6(10)$ & $54(90)$ & 0.16 & $0.02-1.19$ & 0.07 \\
\hline Skilled & $1(4.5)$ & $21(95.5)$ & 0.06 & $0.01-0.95$ & $0.04 *$ \\
\hline \multicolumn{6}{|l|}{ Marital status } \\
\hline Single & $2(28.6)$ & $5(71.4)$ & 1.00 & & \\
\hline Married & $21(11.8)$ & $157(88.2)$ & 3.01 & $0.28-32.98$ & 0.37 \\
\hline \multicolumn{6}{|c|}{ Had a child below 5 years } \\
\hline No & $12(12.8)$ & $82(87.2)$ & 1.00 & & \\
\hline Yes & $11(12.1)$ & $80(87.9)$ & 5.53 & $1.03-28.30$ & $0.04 *$ \\
\hline \multicolumn{6}{|l|}{ Miscarriages } \\
\hline No & $20(12)$ & $147(88)$ & 1.00 & & \\
\hline Yes & $3(16.7)$ & $15(83.3)$ & 0.53 & $0.13-2.11$ & 0.37 \\
\hline \multicolumn{6}{|c|}{ Intrauterine Fetal Demise } \\
\hline No & $22(12.6)$ & $152(87.4)$ & 1.00 & & \\
\hline Yes & $1(9.1)$ & $10(90.9)$ & 7.22 & $0.33-155.91$ & 0.21 \\
\hline \multicolumn{6}{|l|}{ Neonatal Death } \\
\hline No & $23(12.8)$ & $156(87.2)$ & 1.00 & & \\
\hline Yes & $0(0)$ & $6(100)$ & $1.444 \mathrm{E} 8$ & $0.00-\infty$ & 0.99 \\
\hline \multicolumn{6}{|c|}{ Gestational Diabetes Mellitus } \\
\hline
\end{tabular}




\begin{tabular}{|c|c|c|c|c|c|}
\hline \multirow{2}{*}{ Characteristics } & \multicolumn{2}{|c|}{ Anti-CMV IgG + IgM } & \multirow{2}{*}{ Adjusted OR } & \multirow{2}{*}{$95 \%$ C. I. } & \multirow{2}{*}{ p value } \\
\hline & Positive (\%) & Negative (\%) & & & \\
\hline No & $22(12.1)$ & $160(87.9)$ & 1.00 & & \\
\hline Yes & $1(33.3)$ & $2(66.7)$ & 0.17 & $0.01-2.52$ & 0.20 \\
\hline \multicolumn{6}{|l|}{ Pre-eclampsia } \\
\hline No & $20(11.1)$ & $160(88.9)$ & 1.00 & & \\
\hline Yes & $3(60)$ & $2(40)$ & 0.03 & $0.002-0.41$ & $0.01 *$ \\
\hline
\end{tabular}

* significant at $\mathrm{p}<0.05$

\section{Discussion}

The high prevalence of CMV infection noted in this study is similar to what obtains in many developing, low- and middle-income countries (LMIC) [11-15]. Some of the world's highest birth rates and largest populations are found in these LMIC. With the ubiquitous nature of CMV, it means that the cumulative figures of babies with CMV infection in these nations may be enormous [10].

Curiously, a significant proportion of the congenital CMV cases in developing nations result from non-primary infections, whose aetio-pathogenetic processes are less well understood when compared with primary maternal CMV infections [10]. Although the transmission rates and infection sequelae are higher with primary infections [16], nonprimary infections are commoner, and thus, are likely to contribute significantly to the total cases of congenital CMV [17-19]. In low-resource settings such as ours, facilities for both diagnosis and therapy are not widely available. Since there is no effective vaccine against CMV, emphasizing basic hygiene instructions and health promoting measures to uninfected and paradoxically, even seropositive pregnant mothers, appears to be the approach to adopt in other to prevent maternal infections/re-infections [19-22].

The data from this study showed that $12.4 \%$ of the women were seropositive for both anti-CMV IgG and IgM antibodies. This is similar to $8.1 \%$ from a Kenyan study, but much higher than $1.7 \%$ found by Korean investigators $[11,13]$, and could represent either primary or recurrent maternal CMV infection. Although variability exists in the appearance/persistence of IgM antibodies after primary maternal infection, and in the sensitivity/specificity of commercial testing kits, the concomitant finding of both anti-CMV antibodies should spur further evaluation [7]. Rates of transmission of CMV after primary maternal infection is about $35 \%$ (between $20 \%$ and $75 \%$ ), and $<2 \%$ after non-primary/recurrent infection; higher figures have been documented in LMIC with high prevalence of CMV infection [23]. Since universal screening of pregnant women for CMV infection is currently not recommended [24], selected populations of pregnant women could be targeted for public health interventions in places with higher prevalence of the disease, in other to reduce the infection and transmission rates.

We observed that women with under-5 toddlers were more likely to be seropositive for CMV antibodies. This has been globally acknowledged [23, 25-29], especially in some LMIC, where CMV infection rates can climb to $100 \%$ in early childhood [23]. In seronegative mothers, infection rates of about $50 \%$ per year have been documented when their infants and toddlers were shedding CMV [30, 31]. Hygiene instructions to pregnant mothers regarding contact with urine of infants/toddlers (during diaper change) and saliva (during direct kissing of children) reduced the rate of CMV infection from $42 \%$ to $6 \%$ in a previous study [32].

Our study also revealed that pregnant women who were skilled workers were least likely to have CMV infection. Naturally, this group of workers would occupy the top stratum of the socio-economic ladder. Though results from demographic studies have been conflicting, CMV infection and transmission rates occur less commonly in middle- and upper-income populations in developed nations [33-36].

A novel relationship between active maternal infection with CMV and pre-eclampsia was highlighted by our study. This had not been discussed in the literature before now. Authors have however, suggested the possibility of an infectious aetiology for pre-eclampsia [37-39]. Whether this relationship is causal or casual remains to be determined by further studies.

Presently, there is no consensus on universal screening for $\mathrm{CMV}$ in pregnancy, no effective vaccine for CMV, and routine treatment of pregnant women with hyperimmune globulin or antiviral agents to prevent congenital CMV infection is currently not recommended. Thus, primary preventive measures will constitute the mainstay of management of CMV for now. When pregnant women are targeted for primary prevention, there is evidence that $\mathrm{CMV}$ infection can be reduced by $80 \%$ [7].

This study is not without limitations. Discrimination between primary and recurrent $\mathrm{CMV}$ infection was not undertaken. Also, the longitudinal component of screening the mother-baby pairs for confirmation of vertical transmission was not included because of limited resources. Multicentre studies with greater statistical power and longitudinal design will be needed to achieve these goals.

\section{Conclusion}

More than one-tenth of the population studied were actively infected with CMV. Until vaccination against CMV becomes a reality, hygiene and health instructions on the prevention of CMV should be provided to non-immune women who are, or intend to get pregnant, especially those with pre-school age children under age 5. This should be complemented with welfare packages that will improve the general socio-economic well-being of the populace. Larger multicentre studies should be conducted to identify other risk factors of CMV infection, and women who could benefit 
from targeted public health interventions.

\section{References}

[1] S. Bonalumi, A. Trapanese, A. Santamaria, L. D'Emidio, and L. Mobili (2011). Cytomegalovirus infection in pregnancy: review of the literature. Journal of Perinatal Medicine 5, 1-8.

[2] J. G. Dobbins, J. A. Stewart, and G. J. Demmler (1992). Surveillance of congenital cytomegalovirus disease, 19901991. Collaborating Registry Group. MMWR CDC Surveill Summ 41, 35-39.

[3] M. J. Korndewal, A. M. Oudesluys-Murphy, A. C. M. Kroes, A. C. T. Vossen, and H. E. de Melker (2017). Congenital Cytomegalovirus Infection: Child Development, Quality of Life and Impact on Daily Life. Pediatr Infect Dis J 36, 1141 1147.

[4] A. Carlson, E. R. Norwitz, and R. J. Stiller (2010). Cytomegalovirus infection in pregnancy: Should all women be screened? Reviews in Obstetrics and Gynecology 3, 172-179.

[5] S. B. Boppana, L. B. Rivera, K. B. Fowler, M. Mach, and W. J. Britt (2001). Intrauterine transmission of cytomegalovirus to infants of women with preconceptional immunity. N Engl J Med 344, 1366-1371.

[6] A. Y. Yamamoto, M. M. Mussi-Pinhata, S. B. Boppana, Z. Novak, V. M. Wagatsuma, P. F. Oliveira, et al (2010). Human cytomegalovirus reinfection is associated with intrauterine transmission in a highly cytomegalovirus-immune maternal population. Am J Obstet Gynecol 202, 297.e1-8.

[7] R. F. Pass, and R. Arav-Boger (2018). Maternal and fetal cytomegalovirus infection: diagnosis, management, and prevention. F1000Research 7 (F1000 Faculty Rev), 255 (doi: 10.12688/f1000research.12517.1).

[8] S. M. Price, E. Bonilla, P. Zador, D. M. Levis, C. L. Kilgo, and M. J. Cannon (2014). Educating women about congenital cytomegalovirus: assessment of health education materials through a web-based survey. BMC Women's Health 14, 144. DOI: $10.1186 / \mathrm{S} 12905-014-0144-3$.

[9] S. B. Boppana, R. F. Pass, W. J. Britt, S. Stagno, and C. A. Alford (1992). Symptomatic congenital cytomegalovirus infection: neonatal morbidity and mortality. Pediatr Infect Dis J $11,93-99$.

[10] T. M. Lanzieri, S. C. Dollard, S. R. Bialek, and S. D. Grosse (2014). Systematic review of the birth prevalence of congenital cytomegalovirus infection in developing countries. Int J Infect Dis $22,44-48$.

[11] Z. Mainji, and A. K. Nyamache (2014). Seroprevalence of Cytomegalovirus (CMV) among pregnant women in Thika, Kenya. BMC Res Notes 7, 794.

[12] A. Nawawy, A. T. Soliman, O. Azzouni, S. Amer, M. A. Karim, S. Demian, et al (1996). Maternal and neonatal prevalence of toxoplasma and cytomegalovirus (CMV) antibodies and hepatitis-B antigens in an Egyptian rural area. J Trop Pediatr 42, 154-157.

[13] S. I. Khairi, K. S. Intisar, K. H. Enan, M. Y. Ishag, A. M. Baraa, and Y. H. Ali (2013). Seroprevalence of cytomegalovirus infection among pregnant women at Omdurman Maternity Hospital. Sudan J Med Lab Diagn 4, 45-49.
[14] O. E. Ephraim, O. Oyinlola, V. L. Patrick, U. O. Joseph, and J. E. Charles (2013). Seroprevalence and risk factors for cytomegalovirus infection among pregnant women in southern Nigeria. JMID 3, 123-127.

[15] C. Bello, and H. Whittle (1991). Cytomegalovirus infection in Gambian mothers and their babies. J Clin Pathol 44, 366-369.

[16] K. B. Fowler, S. Stagno, R. F. Pass, W. J. Britt, T. J. Boll, and C. A. Alford (1992). The outcome of congenital cytomegalovirus infection in relation to maternal antibody status. N Engl J Med $326,663-667$.

[17] C. Wang, X. Zhang, S. Bialek, and M. J. Cannon (2011). Attribution of congenital cytomegalovirus infection to primary versus non-primary maternal infections. Clin Infect Dis 52, e11-3.

[18] M. M. Mussi-Pinhata, A. Y. Yamamoto, R. M. Moura-Brito, I. M. de Lima, de Carvalhoe P. F. Oliveira, S. Boppana, et al (2009). Birth prevalence and natural history of congenital cytomegalovirus infection in a highly sero-immune population. Clin Infect Dis 49, 522-528.

[19] J. J. de Vries, E. W. van Zwet, F. W. Dekker, A. C. Kroes, P. H. Verkerk, and A. C. Vossen (2013). The apparent paradox of maternal seropositivity as a risk factor for congenital cytomegalovirus infection: a population-based prediction model. Rev Med Virol 23, 241-249.

[20] S. P. Adler, J. W. Finney, A. M. Manganello, and A. M. Best (2004). Prevention of child-to-mother transmission of cytomegalovirus among pregnant women. J Pediatr 145, 485491.

[21] J. Harvey, and C. L. Dennis (2008). Hygiene interventions for prevention of cytomegalovirus infection among childbearing women: systematic review. J Adv Nurs 63, 440-450.

[22] C. Vauloup-Fellous, O. Picone, A. G. Cordier, I. Parent-duChatelet, M. N. Senat, R. Frydman, and L. Grangeot-Keros (2009). Does hygiene counseling have an impact on the rate of CMV primary infection during pregnancy? Results of a 3-year prospective study in a French Hospital. J Clin Virol 46, suppl 4: S49-53.

[23] R. F. Pass, and B. Anderson (2014). Mother-to-Child Transmission of Cytomegalovirus and Prevention of Congenital Infection. J Pediatric Infect Dis Soc 3, Suppl 1: S2-6.

[24] W. D. Rawlinson, S. B. Boppana, K. B. Fowler, D. W. Kimberlin, T. Lazzarotto, S. Alain, et al (2017). Congenital cytomegalovirus infection in pregnancy and the neonate: consensus recommendations for prevention, diagnosis, and therapy. Lancet Infect Dis 17, e177-e188.

[25] R. F. Pass, and C. Hutto (1986). Group day care and cytomegaloviral infections of mothers and children. Rev Infect Dis 8, 599-605.

[26] M. J. Cannon, J. D. Stowell, R. Clark, P. R. Dollard, D. Johnson, K. Mask, et al (2014). Repeated measures study of weekly and daily cytomegalovirus shedding patterns in saliva and urine of healthy cytomegalovirus-seropositive children. BMC Infect Dis 14, 569.

[27] S. A. S. Staras, S. C. Dollard, K. W. Radford, W. D. Flanders, R. F. Pass, and M. J. Cannon (2006). Seroprevalence of cytomegalovirus infection in the United States, 1988-1994. Clin Infect Dis 43, 1152-1153. 
[28] S. P. Adler (1989). Cytomegalovirus and child day care. Evidence for an increased infection rate among day-care workers. N Engl J Med 321, 1290-1296.

[29] R. F. Pass, C. Hutto, M. D. Lyon, and G. Cloud (1990). Increased rate of cytomegalovirus infection among day care center workers. Pediatr Infect Dis J 9, 465-470.

[30] S. P. Adler (1988). Cytomegalovirus transmission among children in day care, their mothers and caretakers. Pediatr Infect Dis J 7, 279-285.

[31] R. F. Pass, C. Hutto, R. Ricks, and G. A. Cloud (1986). Increased rate of cytomegalovirus infection among parents of children attending day-care centers. N Engl J Med 314, 1414 1418 .

[32] S. P. Adler, J. W. Finney, A. M. Manganello, and A. M. Best (2004). Prevention of child-to-mother transmission of cytomegalovirus among pregnant women. J Pediatr 145, 485491.

[33] S. Stagno, R. F. Pass, G. Cloud, W. J. Britt, R. E. Henderson, P. D. Walton, et al (1986). Primary cytomegalovirus infection in pregnancy. Incidence, transmission to fetus, and clinical outcome. JAMA 256, 1904-1908.
[34] K. B. Fowler, S. Stagno, and R. F. Pass (2003). Maternal immunity and prevention of congenital cytomegalovirus infection. JAMA 289, 1008-1011.

[35] P. D. Griffiths, and C. Baboonian (1984). Intra-uterine transmission of cytomegalovirus in women known to be immune before conception. J Hyg 92, 89-95.

[36] K. Schopfer, E. Lauber, and U. Krech (1978). Congenital cytomegalovirus infection in newborn infants of mothers infected before pregnancy. Arch Dis Child 53, 536-539.

[37] P. von Dadelszen, and L. A. Magee (2002). Could an infectious trigger explain the differential maternal response to the shared placental pathology of pre-eclampsia and normotensive intrauterine growth restriction? Acta Obstet Gynecol Scand 81, 642-648.

[38] D. G. Goulis, L. Chappell, R. G. Gibbs, D. Williams, J. R. Dave, P. Taylor, et al (2005). Association of raised titres of antibodies to Chlamydia pneumoniae with a history of preeclampsia. BJOG 112, 299-305.

[39] J. O. Awoleke, G. O. Ajayi, and O. Adegbola (2012). Prevalence of Chlamydophila pneumoniae antibodies in women with pre-eclampsia in Lagos, Nigeria. West African Journal of Medicine 31, 253-258. 